\title{
El empleo y desempleo en el área del Alto Huallaga.
}

Conforme a los dictados del método de "análisis integral del área" estudiaremos en el presente artículo los datos que nos ofrece el Censo de 1940 para los Departamentos de Junín, Huánuco y San Martín, circunscribiendo nuestras apreciaciones a los fenómenos socio-geográficos por nosotros constatados en diferentes pueblos de los antedichos Departamentos que se hallan dentro de la hoya hidrográfica del Río Huallaga. De esta suerte, cuando empleamos la palabra área nos referimos tactodos los centros surbanos, a los campos agrícolas, a los pastizales naturales, $a_{3}$ los bosques y a los desiertos pétreos que están comprendidos entre las nacientes del Río Huallaga por el Sur y la boca del Río Chonta-yacu, a inmediaciones de Uchiza, por el Norte y entre la Cordillera Central por el Oeste y la Cordillera de Huachón o Azul por el Este.

Habiéndose dividido el Departamento de Junín y dado nacimiento al Departamento de Pasco, nuestras apreciaciones se refieren a los sectores Huallaguinos de las Provincias de Carrión y Pasco del nuevo departamento.

La población económicamente activa de los Departamentos de Huánuco, Pasco y San Martín fluctúa entre un 
$34 \%$ y un $38 \%$ del total de sus respectivas poblaciones, correspondienđo el $34 \%$ a Huánuco, que tiene el mayor número de inactivos; el $36 \%$ a San Martín; y, el $38 \%$ a Pasco, que tiene el menor número de inactivos. (Véase cuadros A. y B.).

Es común a los Departamentos de Huánuco, Pasco y San Martín como lo es a ltodo el Perú que la mayor inactividad corresponda a las mujeres. (Véase cuadro C.). Los tres Departamentos son principalmente agrícolas, correspondiendo la cifra mas baja a Pasco con el.5I \%, la mediana a Huánuco con el $70 \%$ y la más alta a San Martín con el $75 \%$ de la población dedicada a dicha actividad. En los tres Departamentos la actividad que ocupa el segundo lugar es la correspondiente a las industrias de transformación. El tercer lugar en Pasco lo ocupa la minería, por ser este Departamento el que tiene la mayor actividad minera del Perú, pero no significa esto casi nada para el presente estudio ya que los centros de mayor actividad minera del Departamento se encuentran fuera de los límites de nuestra área.

E1 resto de las ocupaciones distribuídas por mụy pequeños porcentajes pueden agruparse por , orden de importancia en la siguiente forma: I.-Ganadería, Selvicultura, Caza y Pesca. 2.- Profesiones y Servicios personales. 3.- - Industrias extractivas (menos minería para Pasco). 4.-Comercio, Crédito y Seguros. 5.-Administración Pública y Servicios de Interés General. 6.-Edificación, Construcción y Reparaciones. 7.-Transportes y Comunicaciones. 8.-Diversas ramas de la actividad no clasificada. (Véase Cuadro D.). 


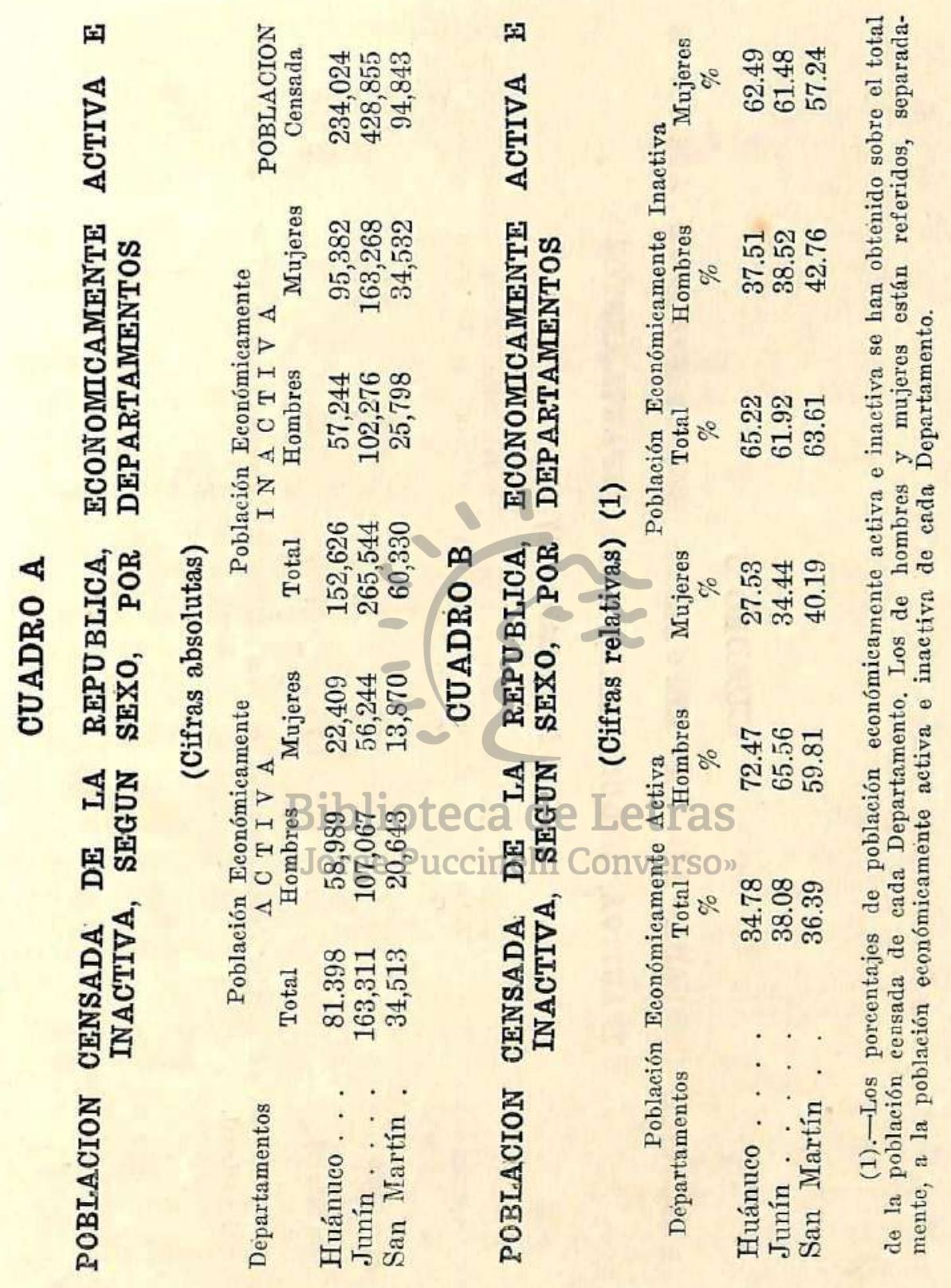




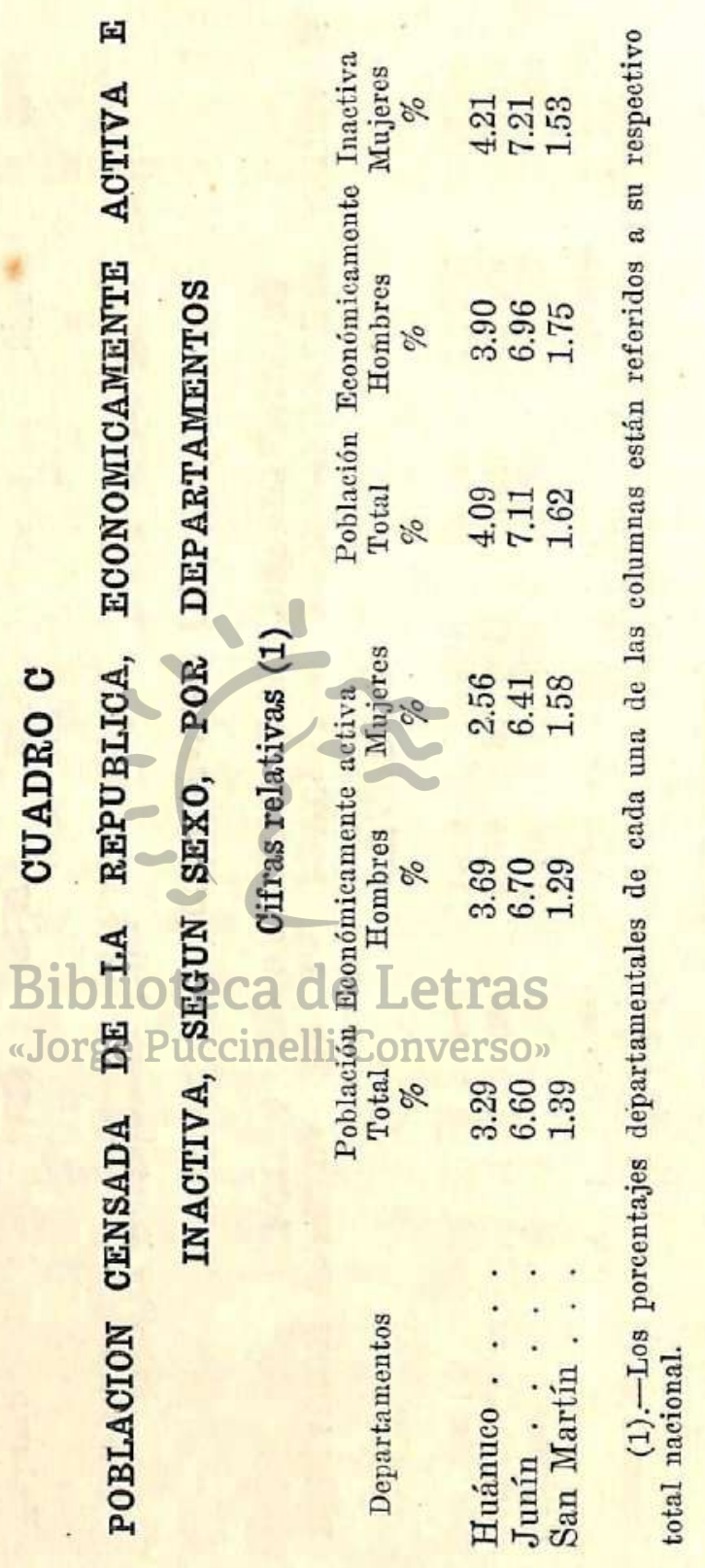




\title{
CUADRO D
}

\section{POBLACION ECONOIVICAIVIENTE ACTIVA DE LA REPUBLICA, SEGUN LAS GRANDES RAIMAS DE ACTIVIDAD ECONOIMICA, POR DEPARTAIMENTOS}

\section{(Cifras relativas) (1)}

\author{
Ramas de Actividad \\ Económica \\ $\%$
}

\author{
DEPARTAMENTOS \\ Huánuco Junín San Martín
}

$\begin{array}{lll}3.29 & 6.60 & 1.39\end{array}$

70.08

51.42

75.69

Agricultura \% . . . .

Ganadería, Silvicultura Ca-

za y pesea \% . . . . . . .

8.31

9.93

1.14

Minería e Industrias Extractivas Similares \% . . .

Industrias de Transformación \% . . . . . . . . Edificación y Construcción y Reparaciones \% . . . . . Transportes y Comunicaciones \% ......... Comercio, Crédito y Seguros \% . . . . . . . Administración Pública y Servicios de Interés General \% Profesiones y Servicios Personales $\%$...... . Otras ramas económicas no Clasificadas \%... . .

(1).-Los porcentajes Departamentales de cada gran rama de actividad económica están referidos a la población económicamente activa de cada Departamento.

Conforme a la orientación agrícola del área y no industrial sino principalmente doméstica, es posible la ocupación de los niños desde los primeros años de la vida. Así, en el Departamento de Huánuco los niños en edad escolar, esto es, entre 6 y I4 años representan el $57 \%$ de la población activa, en Pasco el porcentaje disminuye porque la actividad mi- 
nera no permite el trabajo de los niños muy tiernos; y, en San Martín por razones đe educación y por razones climatéricas que afectan gravemente la salud de los niños, estos no pueden trabajar y el porcentaje se reduce a solo el $30 \%$. En este Departamento la actividad comienza con mayor brío a los I5 años y,empieza a declinar después de los 45 años. Ahí la vida económicamente activa es muy corta, mientras en el Departamento de Huánuco de clima más benigno, con mejores condiciones higiénicas, sanitarias, la vida económicamente activa se inicia, en algunos casos, desde antes de los 6 años y solo comienza a đeclinar después de los $6_{5}$.A esta edad el porcentaje de activos en Huánuco es todavía mayor que en Pasco y San Martín. (Véase cuadro E.).

La población económicamente activa tiene las siguientes principales categorías: 1.-Patrones y dueños, esto es, empleadores y gente que trabaja en la finca propia sin emplear a nadie. 2.-Empleados, que en el área son aquellos que trabajan en negocio ajeno, en labores principalmente intelectuales. 3.-Los obreros que son los que trabajan en labores principalmente manuales en las fábricas, minas o en la agricultura, pero bajo la dependencia de un empleador. 4."Parientes-Colaboradores", aquellos que trabajan en cualquier clase de actividad pero sin ser empleado, ni obrero, ni dueño, sino un dueño potencial e interesado en el negocio. 5.-Independientes, son todos aquellos que trabajan en cualquier clase de actividad sin relación a jefes ni empleados, por lo cual tienen casi.la misma calidad que los dueños de la primera categoría, pero no de bienes inmuebles, si no de su voluntad para trabajar o no, o para elegir a su arbitrio el lugar, el horario y la tarea. (Véase cuadro F.).

Las condiciones de empleo del área, expresadas por las cifras correspondientes al Departamento de Huánuco, son 


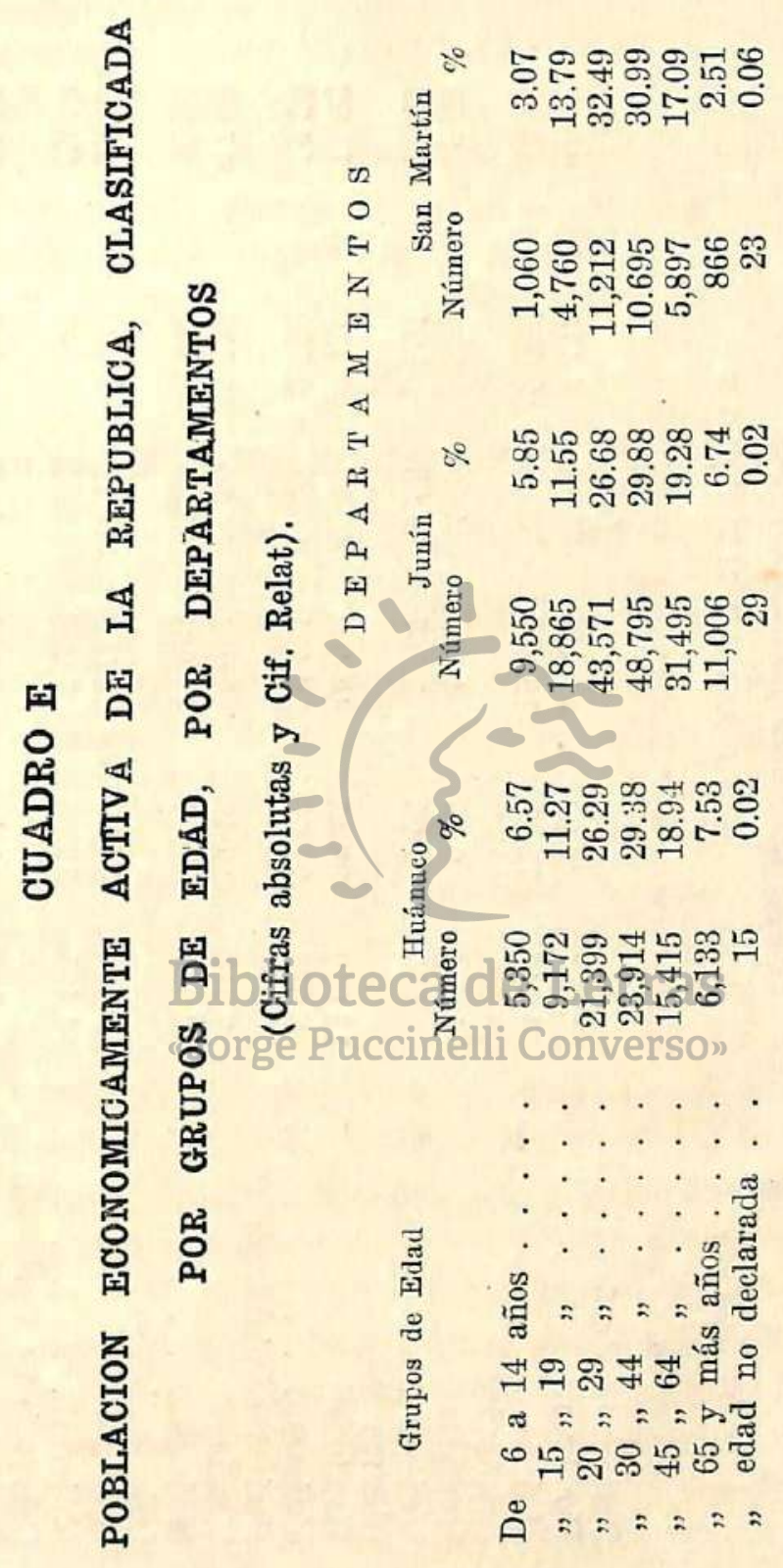




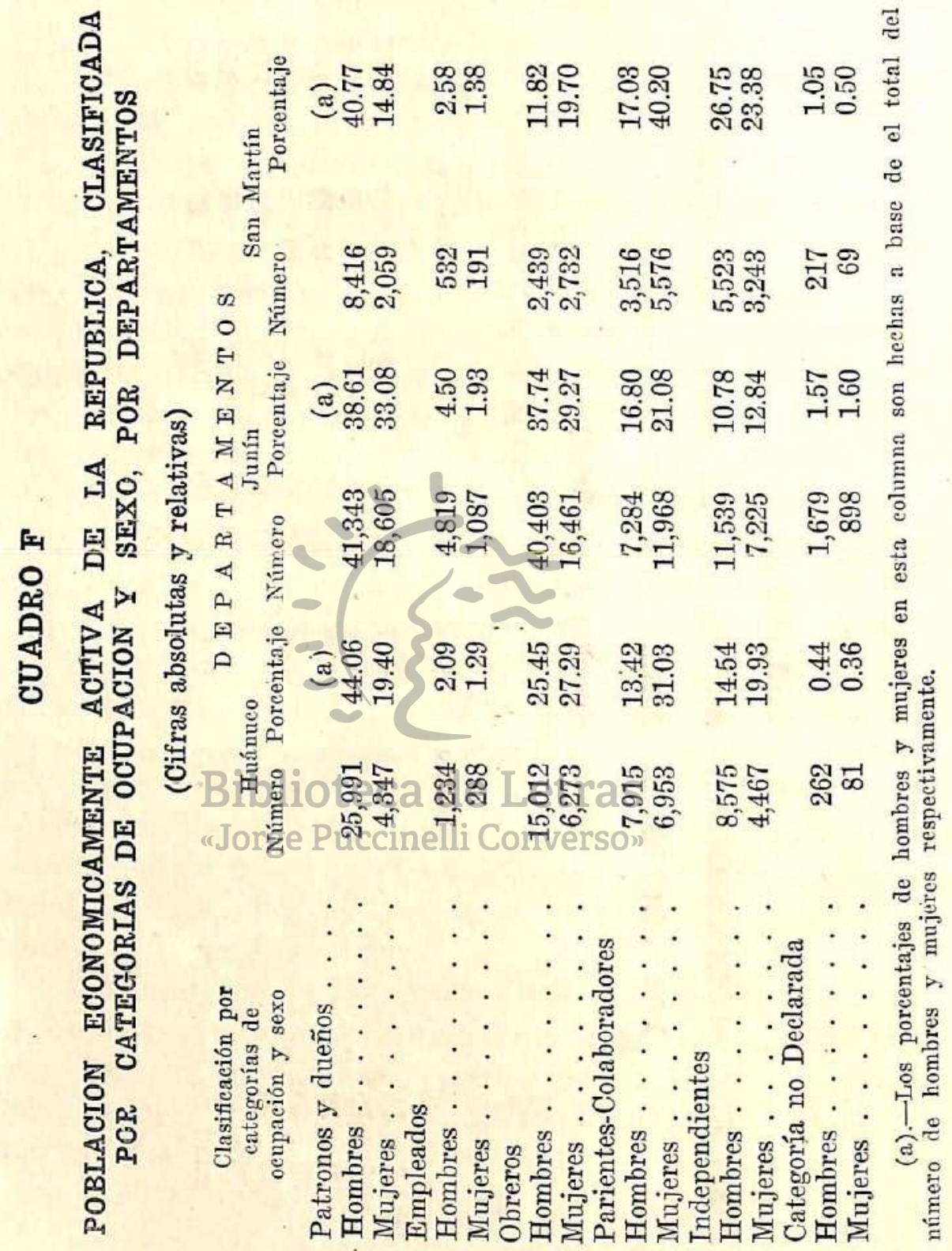


verdaderamente satisfactorias pues tienen la calidad de dueños y patronos el $37.27 \%$, cifra a la cual pueđe ser añadida el $18.26 \%$ de los parientes colaboradores y el I6.02 de los dependientes que también tienen la situación de dueños, con lo cual se evidencia que el 7I.55\% trabajan en negocio propio. Los obreros y jornaleros en general son el 26.I4 \% y los empleados solo el I.86 \% (véase cuadro G.).

\section{CUADRO G}

\section{POBLACION TCONOMICAMENTE ACTIVA DE LA REPUBLICA, CLASIFICADA POR CATEGORIAS Y POR DEPARTAMENTOS}

\section{(Cifras relativas generales para Huánuco)}

Categorias de Ocupacion

Patronos y Dueños . . . . . . .....

Empleados . . . . . . . . . . . .

Obreros . . . . . . . . . . . . .

Parientes Colaboradores

Independientes

Gategoría no Declarada
Huánuco

37.27

1.86

26.14

18.26

16.02

0.42

Esta situaciónces la causa de que la vida sea sin ninguna prisa, sin grandes urgencias pues como cada uno es dueño de su trabajo y de su tarea, suele deferirse las obligaciones a voluntad de cada persona. Así, los artesanos no cumplen jamás con entregar las obras en un plazo fijo, no se puede hacer nada para un tiempo determinado y las gentes han adoptado la perniciosa costumbre de iniciar todas las tareas solo en día Lunes, perdiendo todo el tiempo que media entre la decisión y el lunes de la iniciación de la obra.

Actividad Agrícola.-El aislamiento del área hasta hace pocos años, y la enorme distancią que la separa de sus pocos mercados de consumo, ha condicionado una agricultura 
dedicada exclusivamente a satisfacer sus propias necesidades.

La autarquía económica del área se logró en un Ioo \% durante los primeros años de La Colonia. Los conquistadores aportaron algunos elementos económicos como el trigo, la caña de azúcar, las ovejas, las gallinas, los cerdos, las vacas y los caballos; se adueñaron de todas las tierras que desearon y de la enorme fuerza humana de los indios que les fueron entregados a su cuidado,e hicieron la mas hábil distribución geográfica y económica del trabajo en relación con la estructura social de aquel momento. Comprendieron que no podían continuar exportando ningún artículo, como lo hicieran en los primeros días con el trigo y comprendieron también que los indios anhelaban para lenitivo de sus tristezas, consiguientes al desposeimiento de que habían sido víctimas, la coca que adormece y el alcohol que entusiasma. Por ello prefirieron las tierras productoras de caña, transformando a sus antiguos dueños en operarios de sus haciendas lo que se prueba fácilmente al observar el mapa del "Area de la Caña"đencel cual se descubre antiguas poblaciones cuyos grandes cementeribs aparecen hoy entre los cañaverales. También se hicieron dueños de las plantaciones de coca que los indios tenían en las montañas, principalmente en la cuenca del río Chinchao y las extendieron.

Así, el coquistador españoí tuvo en sus manos a parte de la fuerza política del Estado, las fuerzas invisibles pero poderosas del alcohhol y de la coca, vale decir que tuvo tanto el control de las libertades físicas como de las.sicológicas del indígena. Gracias a estos dos elementos fué facilísimo con muy pocos soldados mantener el orden entre los miles de hombres que se convirtieron en los cultivadores del maíz, las papas, etc. que consumían los blancos de las ciudades y 
en los pastores del ganado que proporcionaban las carnes $y$ las lanas con que se hacía los tejidos en los numerosos obrajes que instalaron los españoles para atenđer a sus propias necesidades de telas y también a las necesidades de los indios.

Esta situación duró toda La Colonia y no se modificó, ni en lo menor, con la independencia, porque razones económicas y sociales basadas en la Geografía las condicionaban así. Hasta hace muy pocos años hemos tenido un área económicamente autárquica en la cual unos pocos blancos y mestizos eran dueños de toda la producción de coca y alcohol de caña, artículos con los cuales comerciaban los indios que a su vez les vendían artículos de primera necesidad a precios muy bajos, ya que el indio jamás había tomado en cuenta el costo de producción ni la rentabilidad, sino que vendía solamente aquellos artículos que le sobraban de su industria doméstica a los precios que le fijaban los hombres de la ciuclad.

Esta autarquía no era del todo absoluta pues los blan$\cos$ y mestizos y los propios indios requerían del comercio exterior para conseguir ciertos artículos como: telas, licores, medicinas, herramientas, colorantes etes $y$ ' en cambio exportaban pequeñas cantidades de coca y aguardiente. Cuando hacia I925 se abrió la carretera Huánuco-Cerro de Pasco, comenzó a cambiar la faz de la economía y ahora que la carretera a Pucallpa ha abierto nuevas rutas al comercio, la evolución económica ha permitido al indio, por primera vez, comparar el monto de los salarios que ha empezado a percibir, en las obras de caminos y colonización con el rendimiento de su actividad en la agricultura que hasta este momento realizaba, dándose cuenta de que es mas ventajoso para él emplearse como jornalero en las nuevas obras que 
seguir trabajando en su propia tierra o en las antiguas haciendas con lo cual ha producido una fuerte convulsión económica al negar su contribución a la agricultura de la época pasada, y al dejar de cultivar grandes áreas de sus propias tierras.

Dicha actitud ha podido ser tomada por muchos de aquellos indios que solían hacer un trabajo estacional, en las áreas de la caña y de la coca, aprovechando del tiempo libre que disponían entre las distintas faenas agrícolas de sus propias chacras y también ha sido tomada por algunos de aquellos otros indios que en calidad de operarios están adscritos a las haciendas los que han comenzado a evadirse, creando un problema a los empleadores pues en muchos casos han percibido una habilitación en dinero y luego han dejado la hacienda, defraudando al patrón.

Por esta causa se ha producido una crisis, principalmente entre los hacendados de la coca, muchos de los cuales han vendido sus haciendas o las han arrendado precisamente a los propios comerciantes de dicho artículo, quienes para resolver la escasez de brazos han elevado los salarios ya que están en condiciones de controlar los precios por ser casi los únicos productores y porque es facil controlar los precios, para mantenerlos altos, en un artículo como la coca cuyo mayor precio es insensible para el consumidor, a quien un alza no le representa sino unas cuantas hojas menos en la ración diaria y quien a su vez por ser el jornalero mejorado no ha opuesto ninguna resistencia.

Pero ha ocurrido también algo muy interesante en cuanto al alza de los precios de los artículos de primera necesidađ producidos por los indios. Al reducirse las áreas cultivadas, han disminuído los volúmenes de producción y los antiguos productores - que ahora ganan un salario mejor- se 
han convertido a su vez en consumidores, por lo cual los precios se han elevado hasta igualarse a los que se pagaban normalmente fuera del área. Con tales. precios es posible que el trabajo en la tierra propia empiece a constituir una actividad mas atrayente y hay el peligro de que los actuales jornaleros que están trabajando en las tierras nuevas de la selva dejen de acudir a ellas, creando la paralización de dicha' naciente actividad agrícola, cuyo poder de absorción de mano de obra va a aumentar cada año, conforme a las leyes de la colonización.

La actividad agrícola es fundamental en el área y ella ha condicionado las diversas sub-áreas, que conforme a los datos del censo y al trabajo de campo realizado sabemos que dan ocupación en la siguiente forma:

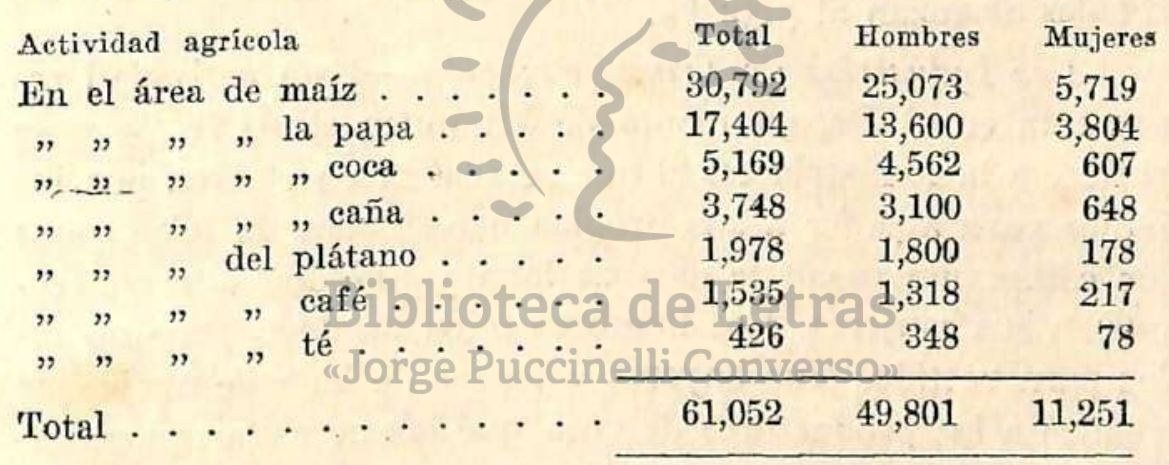

Conforme a este cuadro resulta que el $75 \%$ de la población del Departamento de Huánuco se dedica a la agricultura; pero como en 1940 esta actividad solo alcanzaba al $70.08 \%$, ha habido un incremento del $5 \%$ explicable por las siguientes razones:

I.-Que propiamente a partir de 1940 las obras de colonización han dado nacimiento a dos nuevas áreas agrícolas que las estudiamos con los nombres de áreas del té y del plátano. 
2.-Que a estas dos nuevas áreas han acudido de diferentes lugares trabajadores con sus familias que representan un aumento del $2,05 \%$.

3.-Las, dificultades creadas por la guerra al transporte, a las pequeñas industrias y al comercio y los mejores precios de los artículos de primera necesidad, han provocado una mayor dedicación ;a la agricultura en las áreas del maíz y de la papa.

Otras actividades No Agricolas.-Todas las demás actividades reunidas representan solo el 25 \% de la población económicamente activa. De este porcentaje casi el ig \% se reparte entre Industrias de transformación y ganadería, restando un $6 \%$ para 5 grupos de las mas diversas actividades, entre las cuales las profesiones liberales y los servicios personales alcanzan al $3.52 \%$.

Las Industrias de Transformación.-Esta actividad representa en el Departamento de Huánuco el $10.5^{\mathrm{I}} \%$ y se refiere a la industria textil que se realiza en el área por los indios para atender a sus propias necesidades de telas, pues los campesinos usan tejidos de lana y algodón que confeccionan sus mujeres. Los hombres tejen también pero no telas para vestides sino bayetas y jergas cle lana de oveja que venden a los productores de coca que las necesitan para hacer los sacos en que empacan las hojas a fin de que se conserven en buen estado por un largo tiempo. Los hombres se dedican también a la fabricación de frazadas. Es interesante anotar que mientras en general en el área las mujeres trabajan en un porcentaje muy reducido respecto de los hombres en esta activiđad textil hay solo 618 hombres y 4,301
mujeres.

Lo que significa que la obligación de vestir a la familia reposa exclusivamente sobre la mujer, la cual cumple per- 
fectamente su deber, aunque con las limitaciones de la "callhua" o pequeño telar de madera de factura indígena que es el único equipo que emplea para tejer.

Esta actividad forma parte de la educación tradicional xle las gentes del área a tal extremo que las mujeres jóvenes hacen radicar su mayor atracción y valía personal en el uso de numerosas mantas tejidas por ellas mismas. Tal el caso de Panao en que a veces las jóvenes solteras llevan sobre si hasta 12 , mantas blancas y cremas, según sean de algodón o lana, dispuestas con mucha armonía y usadas con mucho orgullo.

En este renglón de actividades, está al borde de la desaparición la antigua y próspera industria de arneses para cabalgaduras, arte del trenzado de cuero y de talabartería que dió ocupación a muchas gentes pero que ahora con la desaparición del transporte por acémilas ya no constituye mas que una curiosidad.

En Tingo María está naciendo una importante inđurstria de tejido de bejucos con las cuales se fabrican a mano muebles muy resistentèsoy prinorosos. A Arcargo de la enseñanza hay un profesorepagadon por eloGobierno y ya son varíos los jóvenes que se dedican a la fabricación de muebles de mimbre que podrán tener un buen mercado en Lima y quizás hasta en el extranjero.

La industria de curtiduría tuvo un marcado desarrollo en la Provincia de Pachitea, pues los indios disponían de los cueros de los animales sacrificados en el área, empleaban sustancias vegetales como la corteza del árbol magche-magche que crece en el área en los bosques de las alturas y vendían muy baratas buenas suelas con las cuales los zapateros dit Panao realizaban la única industria que por muchos años se desarrolló en la capital de aquella Provincia. Hoy día los 
cueros crudos tienen mas valor que los curtidos y las fábricas de calzados de Lima han invadido los mercados de Huánuco fabricando tipos semejantes a los que se hacían en Panao.

No hay industria de pieles aun cuando es posible desarrollar la de nutria pues el río Huallaga of rece. un habitat propicio para dicho animal y del cual existen especies salvajes de piel muy fina que en la región recibe el nombre de lobo de río.

Poca gente se dedica a la extracción y tejido de la fibra cle la cabuya, la cual es una planta muy abundante y podría ciar nacimiento a una industria organizada y estable, ya que hay grandes extensiones de tierras que no se pueden cultivar con otras plantas pero en cambio son muy propicias a la cabuya. En la actualidad se explotan apenas pequeñas cantidades para atender a las demandas domésticas de cordelería y a la fabricación de los cohetes y petardos que la emplean como empaquetadura.

Ganadería, Selvicultura, Pesca y Caza.-De todas estas actividades solo tiene alguna importancia la ganadería que da ocupación a 2,724 hombres y 3,919 mujeres. La ganadería de ovinos emplea ${ }_{5} 52$ hombres y a 1,134 mujeres. Todos los demás están dedicados a la cría de otros tipos de ganado tales como vacunos y porcinos, siendo casi nula la ganadería de equinos y caprinos y verdaderamente nula la de auchénidos, aunque estos animales tienen en el área grandes extensiones propicias para su desarrollo y según refieren Las Crónicas, la región estuvo muy poblada por llamas, huanacos y vicuñas. Los auchénidos ${ }^{\circ}$ o se utilizan mas que como animales productores de lana y como bestias de transporte, aunque son muy poco resistentes. También en algunos lugares del Perú se les emplea como productores de carne, rol en el cual 
podrían constituir para el ćrea una parte de la solución al problema de la escasez de carnes.

Los pastores del área son una verdadera contradicción social-geográfica, pucs aunque tienen por función vivir para criar animales no viven a expensas de ellos, sino de la agricultura que la gan 'ería permite desarrollar. Es pues una ganadería que no tiene por finalidad la producción de carnes, leche, mantequilla o queso, sino guano para abonar los campos de cultivo, lanas para hacer los vestidos, fuerza para halar los arados. Es un pastor que vive como agricultor. Esta circunstancia se basa tanto en la reducida cantidad de los rebaños cuanto en que de ordinario el pastor apacienta rebaños ajenos de los culales no puede disponer.

Las pesca fué una buena ocupación y todavía se practica en pequeñas proporciones en el río Huallaga por los habitantes de Uchiza pero se ha empleado siempre el método parasitario de la pesca por medio del barbasco o cube que consiste en envenenar todas las aguas đẹl río en muchos kilómetros de recorrido obteniendo por una sola vez una buena cantidad de pescado, pero dejando exterminadas todas las especies de peces en el río por mucho tiempo. En el orden a esta actividad el Gobierno ha sembrado recientemente alevinos de truchas en los ríos l'anao, Higueras y alto Huariaca En este último, hay actualnente alguna cantidad de truchas arco iris que dan lugar solo a la pesca deportiva.

La pesca por anzuelos se realiza en el río Huallaga y sus afluentes, especialmente en las proximidades de la ciudad de Huánuco y Ambo, en donde se pescan dos varìedades de peces pequeños llamados bagres y cachuelos. Se realiza en la forma mas anárquica imaginable, sin control de ninguna clase ni en el tiempo ni en los métodos, por lo cual hay cada vez menor santidad de pescado en el mercado. En 
el área de la coca la pesca constituye una de las peores ocupaciones que puede realizar el poblador pues para ello van, los hombres, a las orillas de los ríos provistos de aguardiente y coca y con el pretexto de la pesca chacchan y se emborrachan y son picados por los zancudos y las malas noches acumuladas concluyen enfermando a los pescadores. De suerte que esta pesca es una verdadera desgracia social, pues tiene la rareza de atraer con violencia al pescador, sin ninguna utiliđad económica y con grave perjuicio para la salud. Felizmente el número de la gente que se dedica a ella es redt1cida.

Los Servicios Personales.-En esta actividad están ocupados 838 hombres y 2,027 mujeres de los cuales el número mas alto corresponde a los sirvientes, que son 585 hombres y i 7 Io mujeres. Hay que indicar la particularidad de este género de ocupación consiste en la evasión de las mujeres del campo hacia la ciudad, pues muchas huyen de la casa paterna para hacerse sirvientas en la ciudad, donde fácilmente se asimilan a las costumbres urbanas. Muy pocas son las que regresan ateff pueblo de origen y mas bien se encargan de hacergel trastado de sus parientes que encuentran trabajo inmediatamente ya que las vías de comunicaciones han llevado al área una población de forasteros que pagan cada vez mejores sueldos a los sirvientes. Las viejas familias de la ciudad solían, tener muchos sirvientes porque lo único que les costaba era la comida que les daban ya que el sueldo fluctuaba entre S/. 3 y 9 al mes; pęro ahora se les paga de S/. I 5. a 3 a al mes, mas casa y comida. La falta de sirvientes constituye un problema serio pues la gente está acostumbrada a que todo se haga por mano mercenaria y, las señoras de buena situación social consideran muy poco distinguido el cocinar y barrer, así como el lavar, por lo cual 
岁

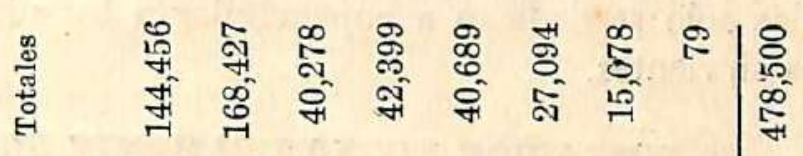
章

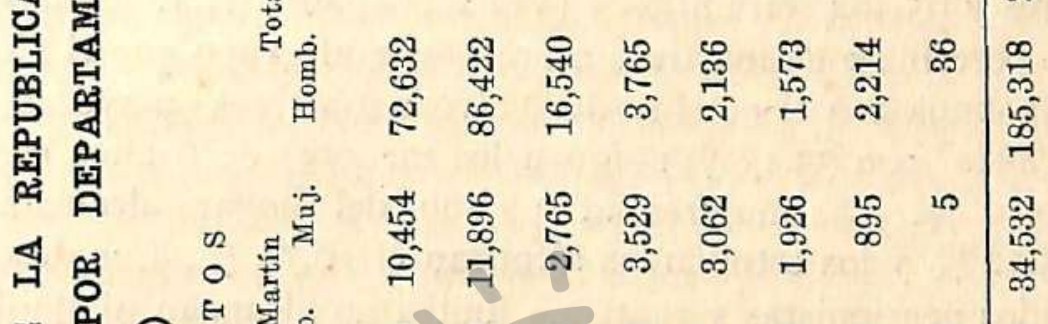

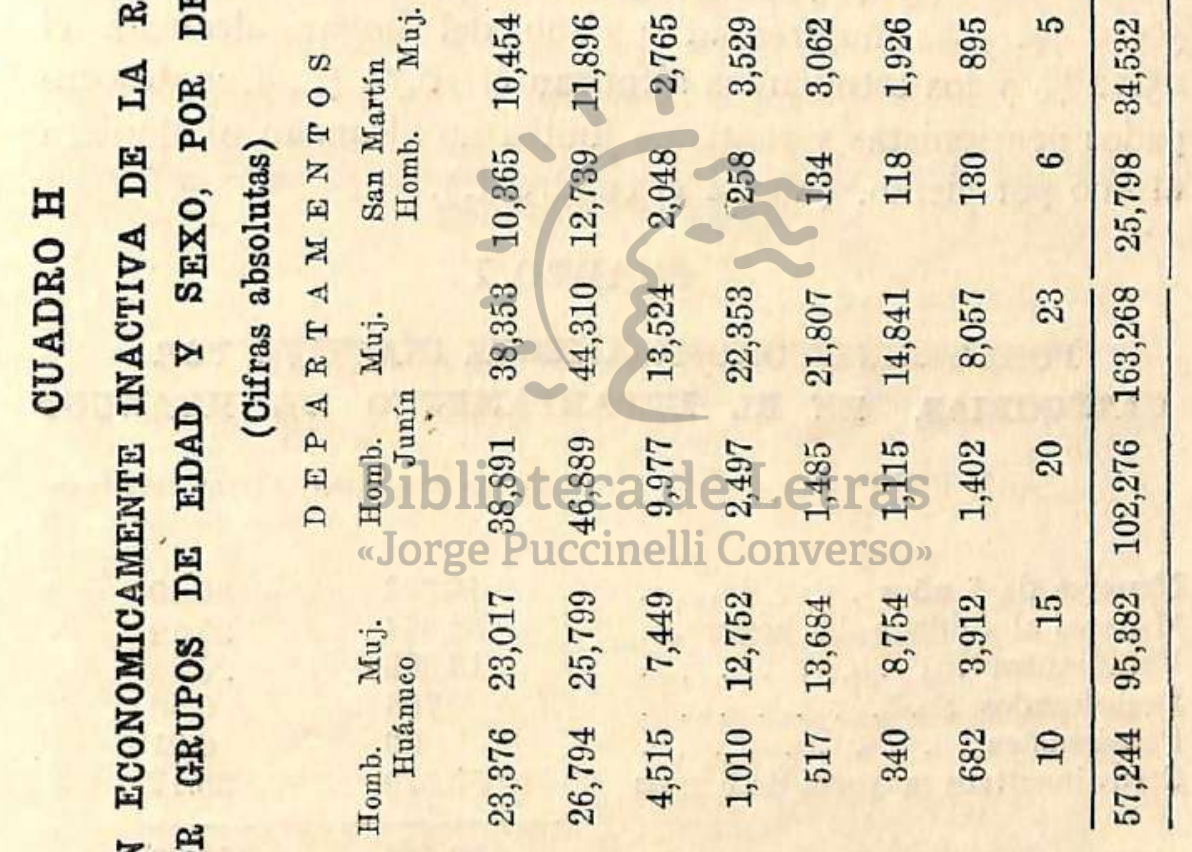

능 영

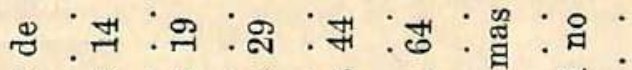

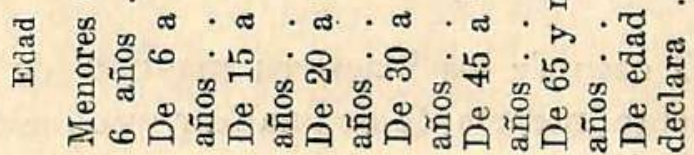


ellas solo se dedican a supervigilar a los niños y mandar a los sirvientes.

\section{POBLACION ECONOIMICAIIENTE INACTIVA}

La población económicamente inactiva del Departamento de Huánuco es de 152,626 , de los cuales 57,224 son hombres y 95,382 son mujeres (véase el cuadro $\mathrm{H}$.). El mas alto porcentaje de inactivos corresponde al grupo que el Censo denomina con el nombre de "otros inactivos mayores de' 6 años" con $33.17 \%$; siguen los menores de 6 años con; el $30.40 \%$. Las mujeres al ridado del logar alcanzan el $25.12 \%$ y los estudiantes alcanzan el 10.74 \%. Los desocupados pensionistas y rentistas juntos no alcanzan ni siquiera al uno por ciento. (Véase el ctradro I.).

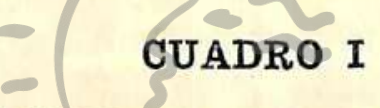

\section{POBLACION ECONOIICANIENTE INACTIVA POR CATEGORIAS, EN EL DEPARTAMENTO DE HUANUCO} G R UP O S teca de Cifras absolutas cirras relativas

Menores de 6 años...... Mujeres al cuidado del hogar. Estudiantes . . . . . . . Desocupados . . . . . . Pensionistas . . . Otros inactivos mayores de 6 años

\begin{tabular}{rr}
46.393 & 30.40 \\
38.344 & 25.12 \\
16.396 & 10.74 \\
768 & 0.50 \\
20 & 0.01 \\
50.629 & 33.17 \\
\hline 152.626 & 100.00
\end{tabular}

El caso de los inactivos mayores de 6 años es verdaderamente interesante de analizar pues se trata de una fuerte población que no produce para el área y que podía constituir una carga muerta y ser la causa del atraso económico 
de la región, si es que, afortunadamente, en su mayor parte, en el $79.49 \%$, no estuviera formada por niños entre $6 y$ I4. años. Estos son los niños en edad escolar que no asisten a la escuela ni se dedican a ninguna ocupación económica remunerada. Muchos de ellos trabajan en la casa paterna, especialmente las niñas del campo que como es bien sabido en el área son muy laboriosas y sirven de gran ayuda a la mamá en las funciones domésticas. Cuando las escuelas sean $\tan$ numerosas que permitan la instrucción de toda esta población, el número de otros inactivos se habrá reducido a solo un quinto de su actual importancią. (Véase cuadro J.).

\section{CUADRO J}

OTROS INACTIVOS MIAYORES DE 6 AÑOS POR GRUPOS DE EDAD Y SEXO

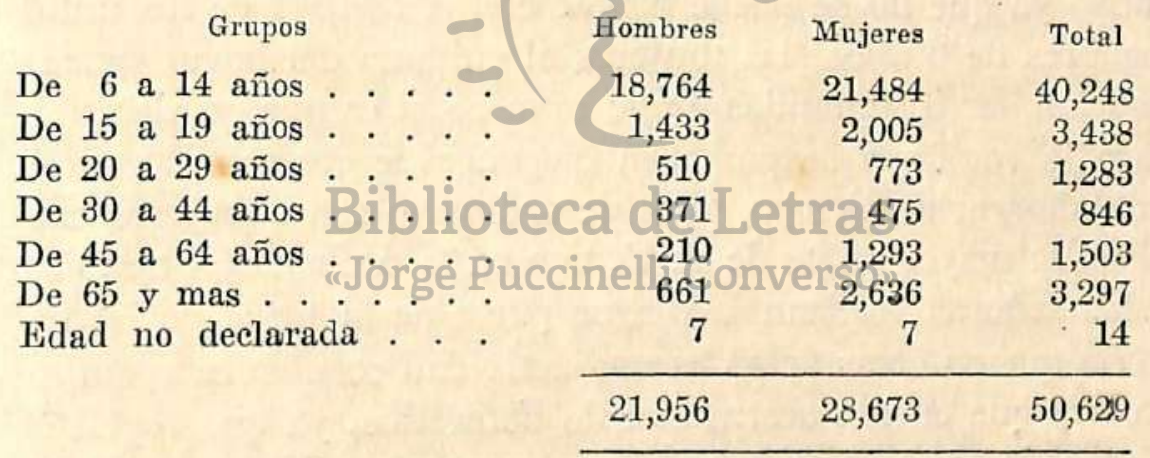

Los jóvenes entre I 5 y 19 años que no estudian ni trabajan son en número de 3,438 , igual al $6,79 \%$ de los "otros inactivos mayores de 6 años". Este grupo está constituído en su mayor parte por mujeres que aguardan matrimonio y que realizan actividad doméstica no remunerada, razón por la cual aparecen como inactivas. Mas peligroso es el caso de los hombres de este mismo grupo, pues de ordinario es- 
tos no se đedican a actividad económica, ni trabajan en nada para sus propias casas, pues suelen ser un tanto inadaptados no cursan estudios secundarios o porque no tienen capacidad para ello o porque no tienen orientada su vocación. A esta edad la autoridad paterna suele ejercerse un tanto disminuída, por lo cual este grupo de jóvenes ofrece un grave peligro para la sociedad ya que algunos de ellos suelen dedicarse a la embriaguez y a una peculiar bohemia que consiste en buscar fiestas y vivir a expensas de ellas, sin trabajar en nada. Debo hacer presente que esta situación comienza a partir de los I8 años y dura hasta después de los 23 o 24 afectando a muy pocos jóvenes.

Algunas personas en Huánuco han sostenido que es posible disponer en las nuevas obras del área de toda la población económicamente inactiva; pero realmente ello es solo 111 sueño ya que no se puede contar con el trabajo de los niños menores de 6 años; las mujeres al cuidado del hogar quizás podrían ser disminuídas en su número si es que se electrificara la región y se pudieran disponer de cocinas eléctricas que ahorrarían tiempo, pues de ordinario estas mujeres emplean la mayor parte de su tiempo en la cocina. Así también estas señoras realizan la mayor parte de la tarea de lavandería que en otras áreas es una actividad económica remunerada y que en la nuestra es solo doméstica, ya que según el Censo de I940 en todo el Departamento de Huánuco, dedicados a la Lavandería y Tintorería solo hay 8 hombres $y$ 89 mujeres. Finalmente el standard bajo de la vida obliga a usar la ropa ,remendada, a veces entre los campesinos los remiendos llegan a ser tantos que es imposible saber de que color fué la tela originaria del vestido y los parches de distintas telas se cuentan por cientos: y, esta labor está encargada también a las mujeres al cuidado del hogar. 
El único número de personas con el cual verdađeramente se puede contar es con los 768 desocupados los cuales en la mayoría de los casos mas que desocupados son un tipo especial de vagos pues solo desean trabajar de oficinistas en alguna dependencia del Estado o en las actividades privadas, pero como no encuentran el trabajo acomodado a sus gustos no trabajan y se acostumbran a vivir a expensas de los parientes, ya que en el área el sentido de parentesco es muy singular: obliga a los parientes próximos a dolerse del que tiene una situación económica inestable, pero nadie procura el cambio radical de la mala situación sino que acuden a los paliativos y a las donaciones por misericordia, que concluyen inadaptando al desocupado.

\section{En resumen:}

No hay en el área el problema de los desocupados, pero si hay el problema đe las rentas muy reducidas, razón por la cual la capacidad adquisitiva de la mayoría de las personas es muy insignificante, dando una prueba de ello la pobreza de las casas en las cuales hay muy pocos muebles: lo remendados de los vestidos; lo viejo de los sombreros; una gran parte de la población camina descalza; la gente no se corta el pelo por economía; se afeitan una vez cada quince días o mas; algunas personas toman desayuno sin pan; no comen carne, no leen libros ni periódicos por no comprarlos (la venta del cliario de mayor circulación en la ciudad de Huánuco no pasa de 200 ejemplares). En fin, una serie de costumbres adquiridas por la pobreza que ya es cuatricentenaria en la región; pero que felizmente parece que ha empezado a sacudirse y es posible que en breve saludemos alegres un nuevo día de bonanza y prosperidad general.

Javier Pulgar Vidal. 